\title{
The Strengthening effect of inter-layer cold working and post-deposition heat treatment on
}

\section{the additively manufactured $\mathrm{Al}-6.3 \mathrm{Cu}$ alloy}

Jianglong Gu, $\mathrm{Gu}^{\mathrm{a}, \mathrm{b}}$, Jialuo Ding ${ }^{\mathrm{b}}$, Stewart W. Williams ${ }^{\mathrm{b}}$, Huimin $\mathrm{Gu}^{\mathrm{a},{ }^{*}}$, Jing Bai ${ }^{\mathrm{a},{ }^{*}}$, Yuchun Zhai ${ }^{\mathrm{a}}$, Peihua $\mathrm{Ma}^{\mathrm{a}}$

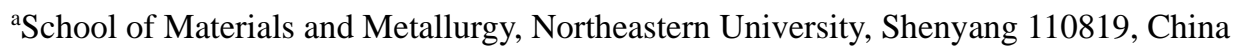

${ }^{\text {b} W e l d i n g ~ E n g i n e e r i n g ~ a n d ~ L a s e r ~ P r o c e s s i n g ~ C e n t r e, ~ C r a n f i e l d ~ U n i v e r s i t y, ~ B e d f o r d s h i r e ~ M K 43 ~ 0 A L, ~ U K ~}$

${ }^{*}$ Corresponding Author, Email: guhm@ smm.neu.edu.cn, baij@neuq.edu.cn, Tel: +86 2483684943

\section{Abstract}

Wire + Arc Additive Manufacture (WAAM) attracts great interest from the aerospace industry for producing components with aluminum alloys, particularly Al-Cu alloy of the 2000 series such as 2219 alloy. However the application is restricted by the low strength properties of the as-deposited WAAM metal. In this study two strengthening methods were investigated - inter-layer cold working and post-deposition heat treatment. Straight wall samples were prepared with 2319 aluminum alloy wire. Inter-layer rolling with loads of $15 \mathrm{kN}, 30 \mathrm{kN}$ and $45 \mathrm{kN}$ were employed during deposition. The ultimate tensile strength (UTS) and yield strength (YS) of the inter-layer rolled alloy with $45 \mathrm{kN}$ load can achieve $314 \mathrm{MPa}$ and $244 \mathrm{MPa}$ respectively. The influence of post-deposition T6 heat treatment was investigated on the WAAM alloy with or without rolling. Compared with inter-layer rolling, post-deposition heat treatment can provide much greater enhancement of the strength. After T6 treatment, the UTS and YS of both of the as-deposited and $45 \mathrm{kN}$ rolled alloys exceeded 450 $\mathrm{MPa}$ and $305 \mathrm{MPa}$ respectively, which are higher than the properties of the wrought 2219-T6 alloy. The strengthening mechanisms of this additively manufactured Al-6.3Cu alloys were investigated through microstructure analysis.

\section{Key words:}

Wire + Arc Additive Manufacture (WAAM); High strength; Aluminum alloy; Rolling; Heat 
treatment

\section{Introduction}

High strength aluminum alloys have been widely used in aeronautic and aerospace industries due to their excellent mechanical properties and high strength to weight ratio [1]. The conventional process of manufacturing aluminum alloy components is by machining the components out of a solid block. Nowadays Additive Manufacture (AM) techniques have been considered by many industries as an alternative economic process for producing metal components [2] due to the benefits in materials cost and lead times saving. Among different AM processes, Wire + Arc Additive Manufacture (WAAM) is attracting significant interest due to the high deposition rate, comparatively low equipment and materials cost, and the capability of building large scale components [3]. The WAAM process employs an electric arc as a heat source and wire for feedstock, depositing material layer by layer [4]. Requirement received from the aerospace industry is to apply WAAM technology for building high strength aluminum alloy structures, particularly Al-Cu alloy of the 2000 series.

$\mathrm{Al}-\mathrm{Cu}$ alloy such as 2219 is an attractive material applied in aerospace applications such as cryogenic tanks, fuselage or shells for space vehicles [5]. The ultimate tensile strength (UTS) of the wrought $2219-\mathrm{T} 8$ alloy is $455 \mathrm{MPa}$ [6]. Comparatively the additively manufactured WAAM 2219 alloy has a much lower strength property (UTS: $260 \mathrm{MPa)}$ in the as-deposited condition [7]. For most of the industrial applications, the strength of the deposited WAAM aluminum alloys needs to be enhanced to a level similar to wrought alloys. Since aluminum alloy 2219 is a precipitation hardened $\mathrm{Al}-\mathrm{Cu}$ alloy, the most common strengthening method is heat treatment. Solution treatment and aging (T6 temper) are often performed in order to improve the strength. During solid solution, the alloying element $\mathrm{Cu}$ is nearly completely dissolved into the aluminum matrix. The solutionized 
$\mathrm{Cu}$ elements then fall out of the solution, nucleate and form different types of precipitates during the subsequent aging, acting as reinforcing phases. The precipitation sequence in the Al-Cu alloy is: Guinier-Preston (GP) zones $-\theta^{\prime \prime}$ phase $-\theta^{\prime}$ phase $-\theta$ phase. The GP zones are monoatomic layers of $\mathrm{Cu}$ on $\mathrm{Al}\{100\}$; the $\theta^{\prime \prime}$ phase grains are thin disks, fully coherent with the matrix; the $\theta^{\prime}$ phase grains are disk shaped and semi-coherent; the $\theta$ phase grains are incoherent interface, disk-shaped [8]. Many researchers have studied the microstructure and mechanical properties of precipitation hardened arc welded joints of aluminum alloy 2219 [9-11]. The tensile strength of these joints can be improved to various levels by different heat treatment regime. Malarvizhi et al. [12] attributed this improvement to the fine and uniformly distributed metastable precipitates.

Another cold working strengthening process - rolling - has been applied to aluminum alloy welds to improve mechanical properties. For example, Ringer et al. [13] and Rao et al. [14] reported that rolling could improve the tensile properties of the welded joints of $\mathrm{Al}-\mathrm{Cu}$ alloy by inducing dislocations. Rolling has also been introduced into the WAAM process by applying to the deposited metal between each and every layer. Colegrove et al. [15] reported the application of this inter-layer rolling technique during building WAAM steel structures, while Martina et al. [16] reported their work of using this technique during the deposition of Ti-6Al-4V alloy. Many benefits of integrating the inter-layer rolling process have been achieved by them, including refinement of grains, improvement of mechanical properties, as well as reduction of distortion and residual stresses. However this inter-layer rolling process has not so far been applied to aluminum alloy additive manufacturing.

The Gas Metal Arc Welding (GMAW) process is commonly chosen for WAAM. However the standard GMAW is likely to generate porosity and large columnar grains, which makes the strength properties worse [17]. Porosity elimination and homogeneous microstructure with refined equiaxed 
grains for the WAAM aluminum metal have been achieved by using pulse advanced Cold Metal Transfer (CMT-PA) process [18], which is a modified GMAW variant based on a controlled dip transfer mode mechanism. The process delivers excellent performance with excellent welding quality, low heat input and is nearly spatter-free [19]. Thus CMT-PA process was employed for deposition throughout this study.

In this paper the effects of applying inter-layer rolling and post heat treatment on strengthening of the WAAM Al-6.3Cu alloy were investigated. Aluminum alloy wire ER2319 (Al-6.3Cu), which has the same nominal composition with wrought aluminum alloy 2219, was employed as the raw material. The deposited metal hereinafter is referred to as WAAM 2219 rather than 2319, since 2219 is the commonly accepted alloy designation in the industry for the wrought product.

\section{Experimental}

The nominal compositions of the commercial ER2319 wire (1.2 $\mathrm{mm}$ in diameter) and the 2219-T87 substrate plates are listed in Table 1. The substrates had dimensions of $300 \mathrm{~mm} \times 60 \mathrm{~mm}$ $\times 19 \mathrm{~mm}$ and were washed in the alkaline water and dried in air. This was then followed by mechanical cleaning and by degreasing using acetone immediately before deposition. Walls were deposited layer by layer in alternative direction along the centerline of the substrates, using a Fronius CMT Advanced 4000R power source. The CMT-PA mode was applied for building the walls. As shown in Fig. 1 a rolling rig was used to move the CMT torch and a flat roller. Compressive pressure was applied on the top surface of each layer by a hydraulic cylinder through the roller. For each sample inter-layer rolling was employed between each and every deposited layer at a constant load. Torch/roller travel speed $(0.6 \mathrm{~m} / \mathrm{min})$, wire feed speed $(6 \mathrm{~m} / \mathrm{min})$, inter-layer cooling time (2 min), shielding gas flow rate $(25 \mathrm{~L} / \mathrm{min})$ of pure argon $(99.99 \%)$ and contact tip to work piece distance $(15 \mathrm{~mm})$ were all kept constant for all the wall samples. The heat input during 
the deposition was maintained around $118.3 \mathrm{~J} / \mathrm{mm}$. The dimensions of the walls are listed in Table

2.

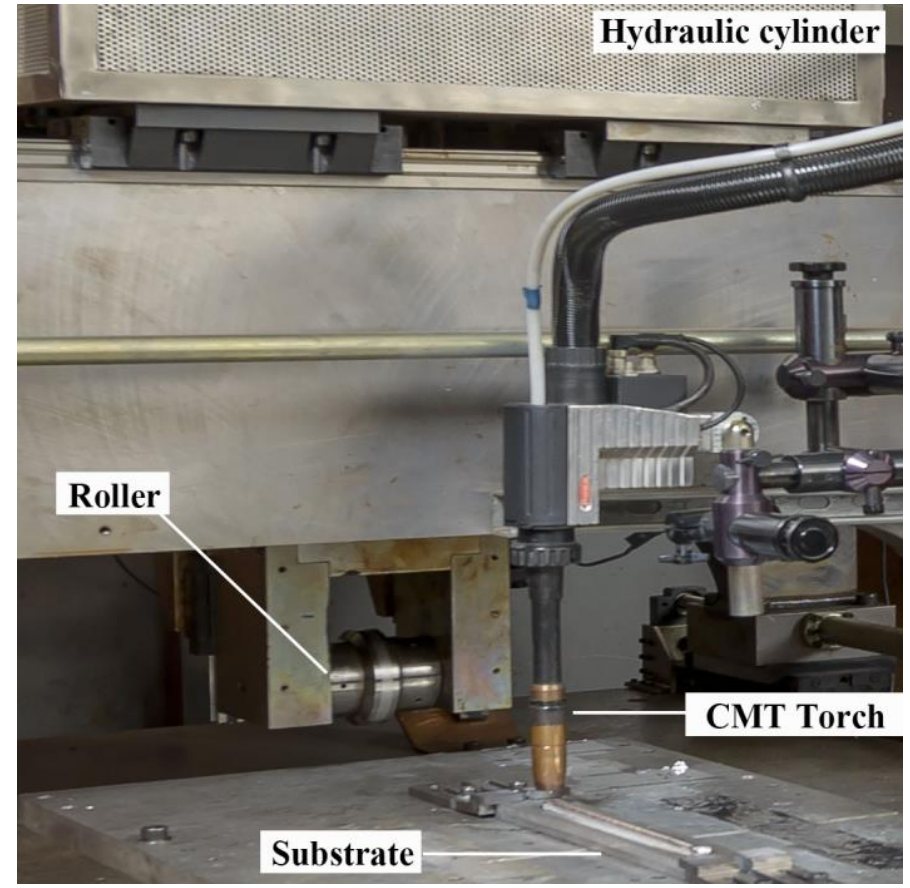

Fig. 1. WAAM deposition and rolling setup

Table 1 Nominal composition of the ER2319 wire and the 2219-T87 substrate.

\begin{tabular}{cccccccccc}
\hline \multirow{2}{*}{ Alloys } & \multicolumn{10}{c}{ Chemical composition (wt. \%) } \\
\cline { 2 - 10 } & $\mathrm{Cu}$ & $\mathrm{Mg}$ & $\mathrm{Mn}$ & $\mathrm{Ti}$ & $\mathrm{Zr}$ & $\mathrm{V}$ & $\mathrm{Zn}$ & $\mathrm{Si}$ & $\mathrm{Fe}$ \\
\hline ER2319 & $5.8-6.8$ & $\leq 0.02$ & $0.2-0.4$ & $0.1-0.2$ & $0.1-0.25$ & $0.05-0.15$ & $\leq 0.1$ & $\leq 0.2$ & $\leq 0.3$ \\
2219-T87 & $5.8-6.8$ & $\leq 0.02$ & $0.2-0.4$ & $0.02-0.1$ & $0.1-0.25$ & $0.05-0.15$ & $\leq 0.1$ & $\leq 0.2$ & $\leq 0.3$ \\
\hline
\end{tabular}

Table 2 Dimension and deformation of the walls.

\begin{tabular}{|c|c|c|c|c|c|c|}
\hline Condition & $\begin{array}{l}\text { Length } \\
(\mathrm{mm})\end{array}$ & Layers & $\begin{array}{l}\text { Total height } \\
\text { (mm) }\end{array}$ & $\begin{array}{c}\text { Mean height } \\
\text { per layer }(\mathrm{mm})\end{array}$ & Wall width (mm) & $\begin{array}{c}\text { Total } \\
\text { deformation }(\%)\end{array}$ \\
\hline As-deposited & 220 & \multirow{2}{*}{44} & \multirow{2}{*}{103.4} & \multirow{2}{*}{2.35} & \multirow{2}{*}{6.8} & \multirow{2}{*}{--- } \\
\hline T6 treated & 220 & & & & & \\
\hline $15 \mathrm{kN}$ rolled & 220 & 50 & 102 & 2.04 & 7.5 & $13.2 \%$ \\
\hline $30 \mathrm{kN}$ rolled & 220 & 60 & 99 & 1.65 & 9.2 & $30.0 \%$ \\
\hline $45 \mathrm{kN}$ rolled & 220 & \multirow[b]{2}{*}{76} & \multirow[b]{2}{*}{99.6} & \multirow[b]{2}{*}{1.31} & \multirow[b]{2}{*}{11.5} & \multirow[b]{2}{*}{$44.2 \%$} \\
\hline $45 \mathrm{kN}$ rolled+T6 & 220 & & & & & \\
\hline
\end{tabular}

Wall samples were prepared with six different conditions. They were as-deposited, post-deposition T6 heat treated, inter-layer rolled with $15 \mathrm{kN}$ load, inter-layer rolled with $30 \mathrm{kN}$ 
load, inter-layer rolled with $45 \mathrm{kN}$ load, and inter-layer rolled with $45 \mathrm{kN}$ load $+\mathrm{T} 6$ heat treated. The overall deformations - compression rate in the loading direction - for the rolled samples with different rolling loads are listed in Table 2. The post-deposition T6 heat-treatment included two steps, which were solution treatment and artificial aging. The samples were ramped in the furnace at a speed of $200{ }^{\circ} \mathrm{C} / \mathrm{h}$ from room temperature to $535{ }^{\circ} \mathrm{C}$ and were kept at this temperature for $90 \mathrm{~min}$ as the soaking time, followed by a cold water quench. Artificial aging treatment was then carried out at $175{ }^{\circ} \mathrm{C}$ for $3 \mathrm{~h}$ at a ramping speed of $100{ }^{\circ} \mathrm{C} / \mathrm{h}$ from room temperature. Wall samples were then cooled down to room temperature in the furnace.

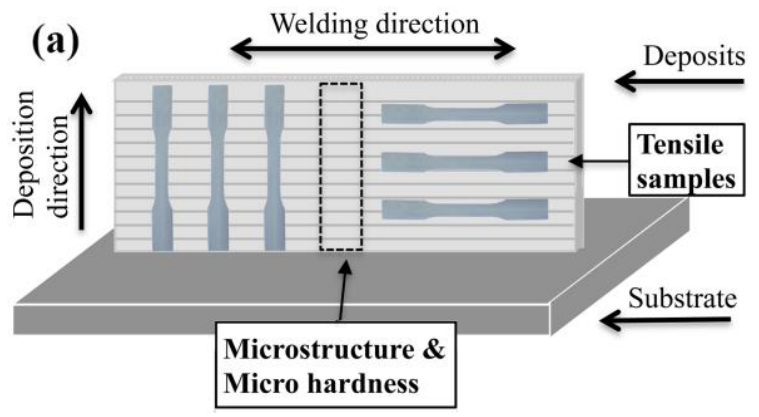

(b)

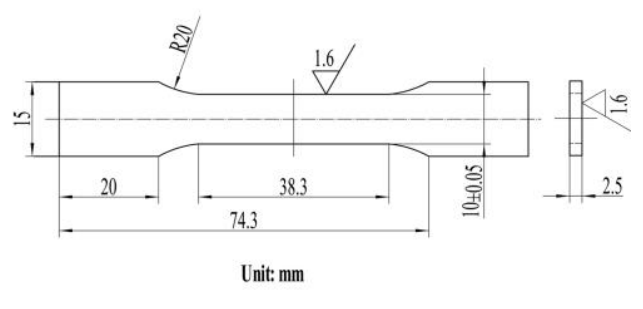

Fig. 2. (a) The sampling positions of each wall; (b) the size of the tensile samples.

Both ends $(10 \mathrm{~mm})$ of each wall sample were cut off and discarded. The sampling positions of each wall were sectioned as shown in Fig. 2 (a). Samples for the microstructure analysis and hardness test were taken from the middle part of the wall. Three tensile test samples along the vertical direction were equidistantly taken from the middle to the end of the wall. Another three tensile test samples in the horizontal direction were evenly taken from the top to the root of each wall. The tensile test samples as shown in Fig. 2 (b) were machined to a final surface roughness less than $1.6 \mu \mathrm{m}$. Tensile tests were carried out at ambient temperature by an electro-mechanical universal testing machine following the BS EN ISO 6892-1:2009 standard. The specimen was loaded with an initial strain rate of $0.005 \mathrm{~min}^{-1}$. Vickers micro hardness testing machine (Auto-C.A.M.S. of Zwick Roell) was employed with $200 \mathrm{~g}$ load for $15 \mathrm{~s}$ for measuring the hardness. 
The hardness test started $20 \mathrm{~mm}$ from the top surface of each wall. 40 tests with an interval of 0.5 mm were taken along the vertical direction and then the values were averaged.

Specimens of cross sections were taken from each wall for microstructure investigation. Optical microscopy (OM) (OPTIPHOT, NIKON), scanning electron microscopy (SEM) (XL30ESEM, PHILIPS), and transmission electron microscopy (TEM) (JEM-2100F, JEOL) were employed for taking images of the microstructure. The epoxy mounted OM specimens were ground with 240, 600, 1200 and 2500 grit $\mathrm{SiC}$ papers under flowing water, then were polished with $3 \mu \mathrm{m}$ diamond paste and colloidal silica suspension to a mirror finish. Etching was performed with Keller's reagent solution. Specimens for SEM were not etched. The $3 \mathrm{~mm}$ diameter TEM foil specimens were mechanically polished to about $200 \mu \mathrm{m}$ and were twin jet electro-polished at $-30{ }^{\circ} \mathrm{C}$ and $15 \mathrm{~V}$ with a solution of $30 \%$ nitric acid and 70\% methanol. Energy dispersive spectrometry (EDS) was used for micro-area composition analysis. Electron backscattered diffraction (EBSD) with a step length of $1.264 \mu \mathrm{m}$ was carried out for grain size and misorientation analysis by using an INCA Crystal EBSD system, Oxford Instruments. Fracture surface morphology of the tensile specimens was performed using SEM.

\section{Results and discussion}

\subsection{Mechanical properties}

Micro hardness test results of the rolled alloys with increased loads of $15 \mathrm{kN}, 30 \mathrm{kN}$ and $45 \mathrm{kN}$ are shown in Fig. 3 (a). Linear trends can be observed between the micro hardness and the rolling load, and between the deformation and the rolling load. For every $15 \mathrm{kN}$ increment of the rolling load, both micro hardness and deformation increased by $13 \%-16 \%$. The micro hardness along the vertical direction of the rolled walls became more evenly distributed with increased loads (Fig. 4), indicating that mechanical properties of the rolled alloy were gradually homogenized. As shown in 
Fig. 3 (b), when the as-deposited and the $45 \mathrm{kN}$ rolled metals were T6 treated, the mean hardness values of them both increased by $111 \%$. Compared with the non-rolled + heat treated sample, the hardness distribution was improved when the WAAM alloy was inter-layer rolled before heat treatment (Fig. 4).
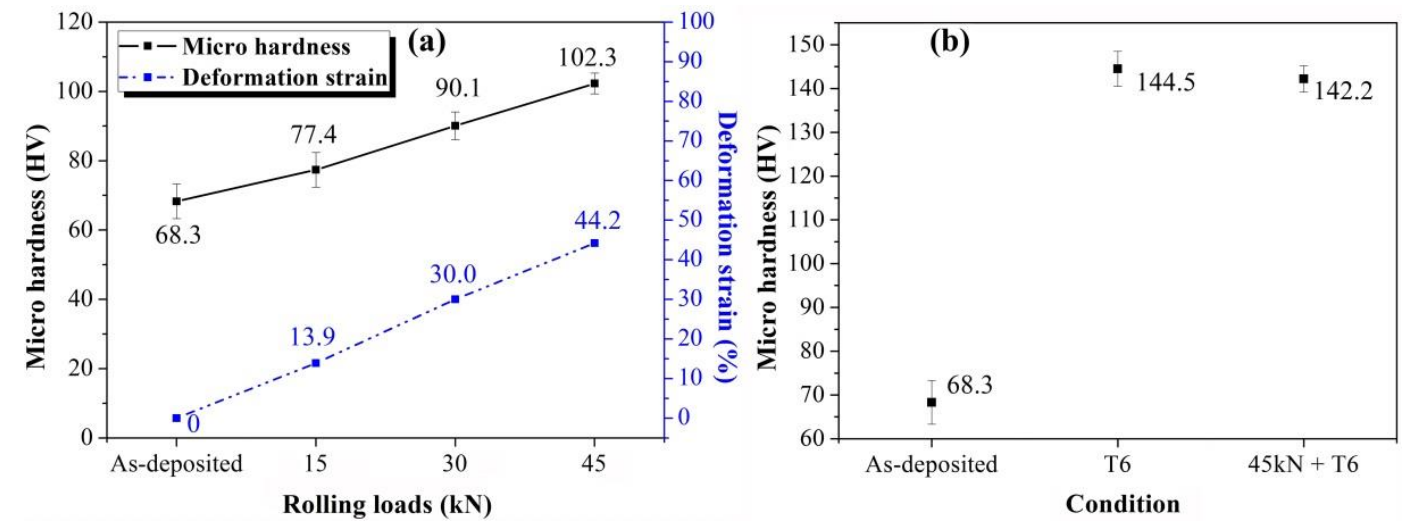

Fig. 3. Micro hardness of the WAAM 2219 alloys with (a) inter-layer rolling and (b) T6 heat treatment.

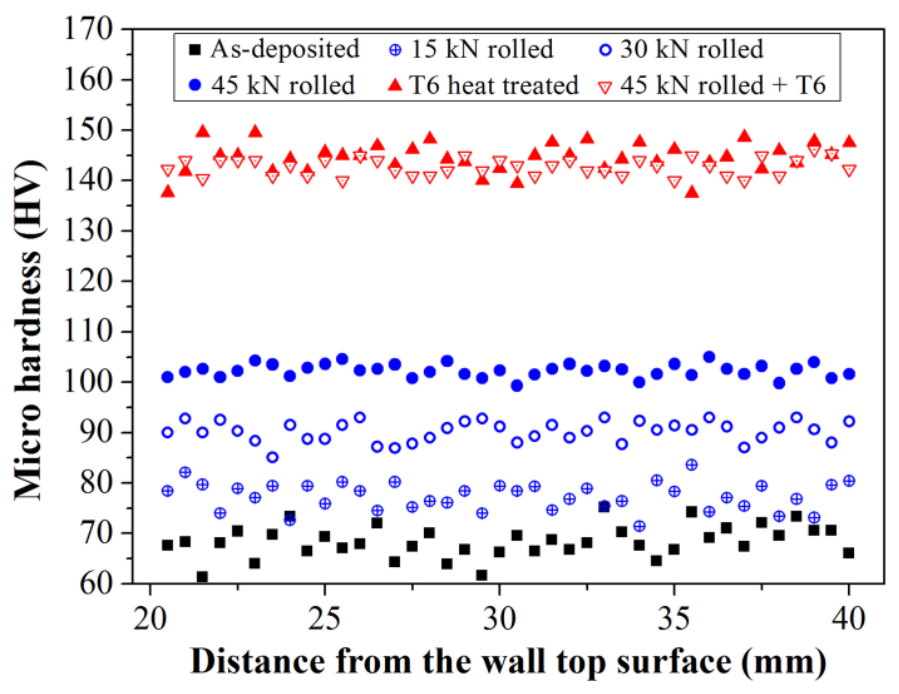

Fig. 4. The micro hardness distribution of the various conditioned WAAM 2219 alloy.

The histograms in Fig. 5 show the ultimate tensile strength (UTS), yield strength (YS) and elongation results from the tensile tests. The strength properties are nearly isotropic with only 0-15 MPa lower in the vertical direction (i.e. across the layers) than that in the horizontal direction. 


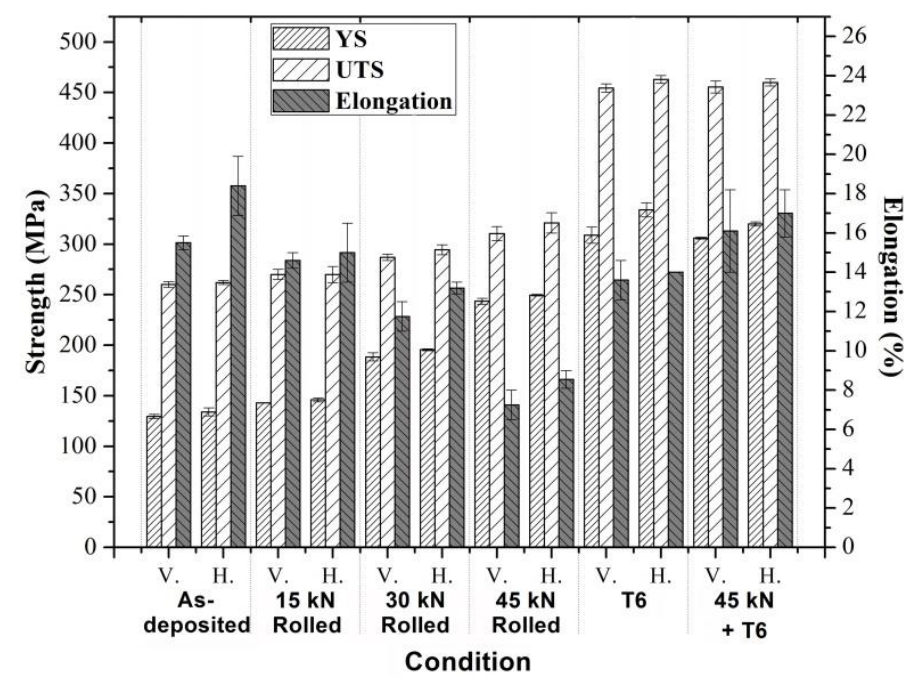

Fig. 5. Tensile properties for the as-deposited, inter-layer rolled and heat treated WAAM 2219 alloys (Where V represents vertical direction; H represents horizontal direction).

There is a linear relation between the rolling load increment and the improvement of UTS and YS with higher rolling load leads to higher UTS and YS. Using the rolling load of $45 \mathrm{kN}$ there is an increase in the UTS of $20 \%$ but a much larger increase in the YS of $87 \%$, with a consequential decrease in the elongation to about $47 \%$. Applying post-deposition heat treatment significantly enhanced tensile properties to more than $450 \mathrm{MPa}$ and $305 \mathrm{MPa}$ for the UTS and YS in the vertical direction of the walls. After post deposition heat treatment there was very little difference in strength between the as-deposited and rolled alloys. The elongation of the rolled T6 treated alloy is 23\% higher than the as-deposited T6 treated one. Joseph [6] recorded that the UTS, YS and elongation for the industrial wrought 2219-T62 tempered alloy are $414 \mathrm{MPa}, 290 \mathrm{MPa}$ and 10\% respectively, which are all lower than the T6 treated WAAM 2219 alloys in this study.

\subsection{Fracture morphology}

Fig. 6 displays the SEM images of the tensile test fractograph morphology in the horizontal direction for the WAAM 2219 alloys under various conditions. All the fractured surfaces consist of dimples, which are regarded as an indication of ductile fracture. The dimple sizes are different with respect to the specimens with various processing conditions. 

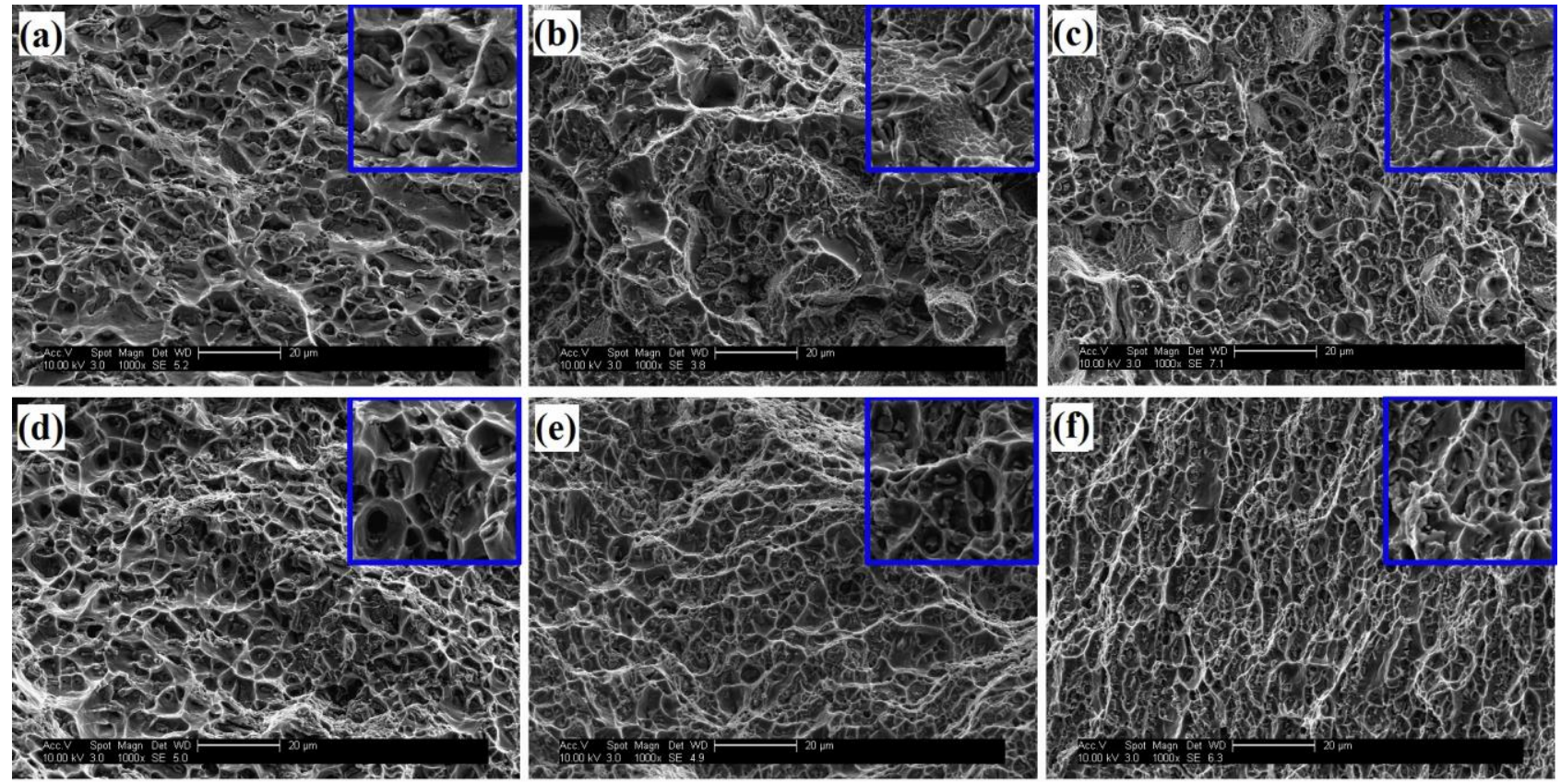

Fig. 6. SEM fractograph morphology for tensile specimens of the WAAM 2219 alloys (a)

as-deposited; (b) after-deposition T6 treated; (c) 45kN rolled + T6 treated; (d-f) $15 \mathrm{kN}$; $30 \mathrm{kN}$ and $45 \mathrm{kN}$ rolled.

As shown in Fig. 6 (a) coarser dimples and cracked second phase particles can be observed on the fractured surface of the as-deposited 2219 alloy. The second phase particles were found embedded at the centre of each dimple, which can cause initiating primary cracks of fracture [20].

Generally the $\mathrm{Cu}$ solute atom depletion zone (SDZ) in the as-deposited alloy are formed around grain boundaries due to the concentrated scattered $\theta$ phase particles along the grain boundaries [21]. These SDZ areas are weaker in strength compared with the other areas. Under static tensile stress, the tearing edges surrounding the particles are generated at these SDZ areas, showing a typical trans-granular fracture mode. Compared with the as-deposited specimen, the dimples size of the rolled specimens became smaller with increased rolling loads as shown in Fig. 6 (d-f). The distribution of the dimples was more uniform with the fractured particles positioned in them. This fracture mode correlates with the increased strength of the rolled specimens. The same ductile fracture mode can be observed for the T6 treated samples with/without rolling. As shown in Fig. 6 
(b) and (c) for the fractured surface of the heat-treated specimens, there were a great amount of fine and shallow dimples with few particles embedded. This is an indication of high strength for the Al-Cu6.3 alloy as reported [22].

\subsection{Microstructure}

Fig. 7(a) shows the OM images of the as-deposited WAAM 2219 alloy. The comparatively low heat input of the CMT-PA process results in a homogeneous microstructure with fine dendrites and equiaxed grains. After inter-layer rolling with loads of 15 kN, $30 \mathrm{kN}$ and $45 \mathrm{kN}$ as shown from Fig. 7 (b-d), the deposited metal was deformed due to plane strain compression. The grains became smaller in size, elongating along the short-transverse direction with freeform deformation.
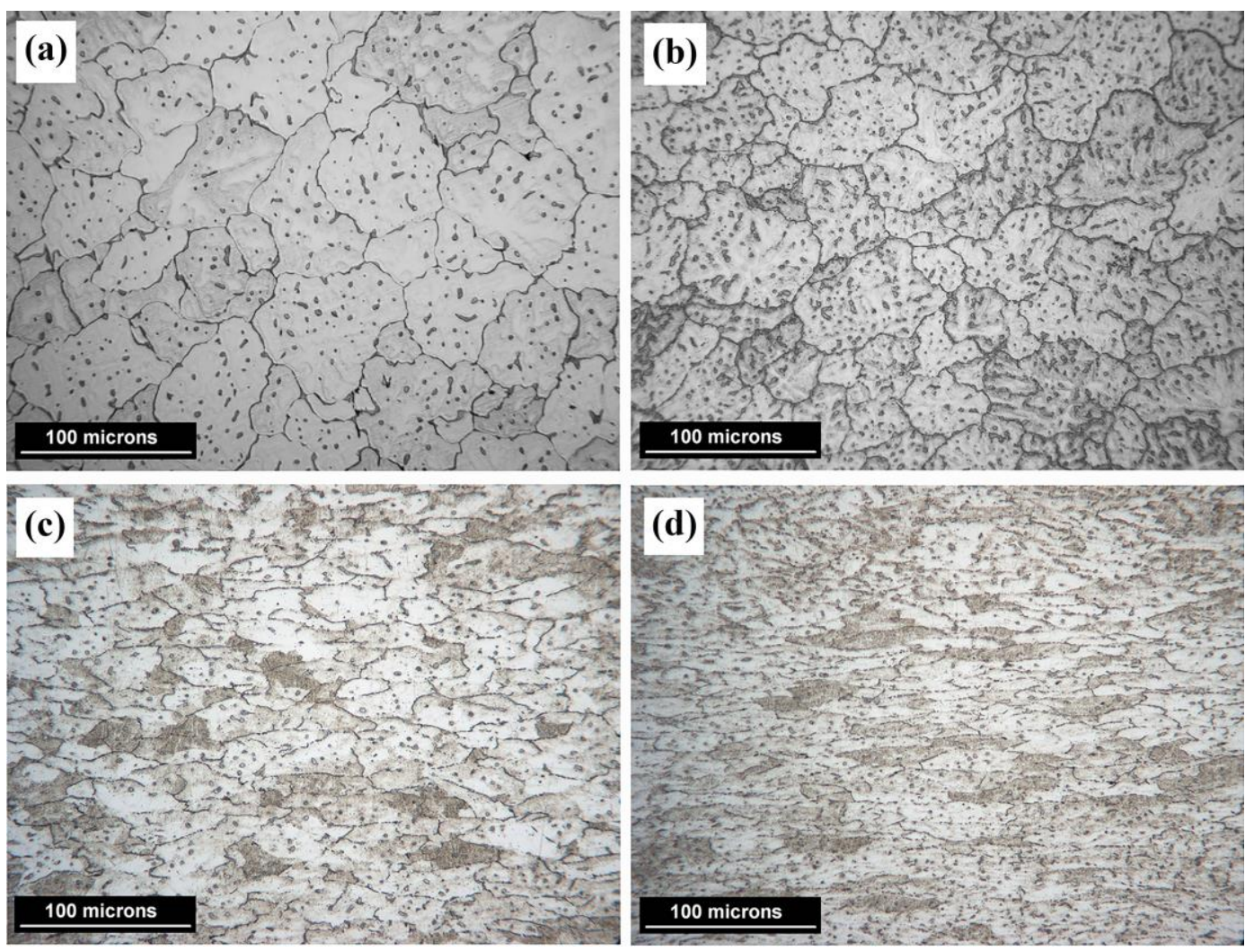

Fig. 7. Optical micrographs for the WAAM 2219 alloys (a) as-deposited; (b-d) 15 kN, 30 kN and 45 $\mathrm{kN}$ inter-layer rolled.

SEM images of the as-deposited alloy and the rolled alloys are shown in Fig. 8. There are white network-like second phase particles scattered along the grain boundaries or distributed in the 
intra-grain regions as shown in Fig. 8 (a). Analyzed using EDS these white phase particles are $\mathrm{Al}-\mathrm{Cu}$ eutectics ( $\alpha$-Al and $\theta$ phases), as shown in Fig. 9 (a). The eutectic composition is $\mathrm{Al}_{61.47} \mathrm{Cu}_{38.53}$ for the as-deposited alloy without heat treatment. Cao and Kou pointed out that for GMAW of alloy 2219, $\theta$ phase particles act as in-situ micro instigators, forming distinct composite-like eutectic particles upon reaching the eutectic temperature [23]. Al-Cu eutectics contain over $30 \% \mathrm{Cu}$, mostly forming along the grain or dendrite boundaries. These $\mathrm{Cu}$-rich particles easily coarsen and are non-uniformly distributed due to the decreased cooling rate during the repeated thermal cycles of the WAAM process. In addition, this segregation generally causes $\mathrm{Cu}$ solute atom depletion zone around the phases, which reduces the mechanical properties [21]. As shown in Fig. 8 (b-d), the eutectic particles were fractured into smaller pieces during the rolling process. A higher rolling load resulted in smaller phase particles. The distribution of these fractured particles was extended in the grain deformation direction.
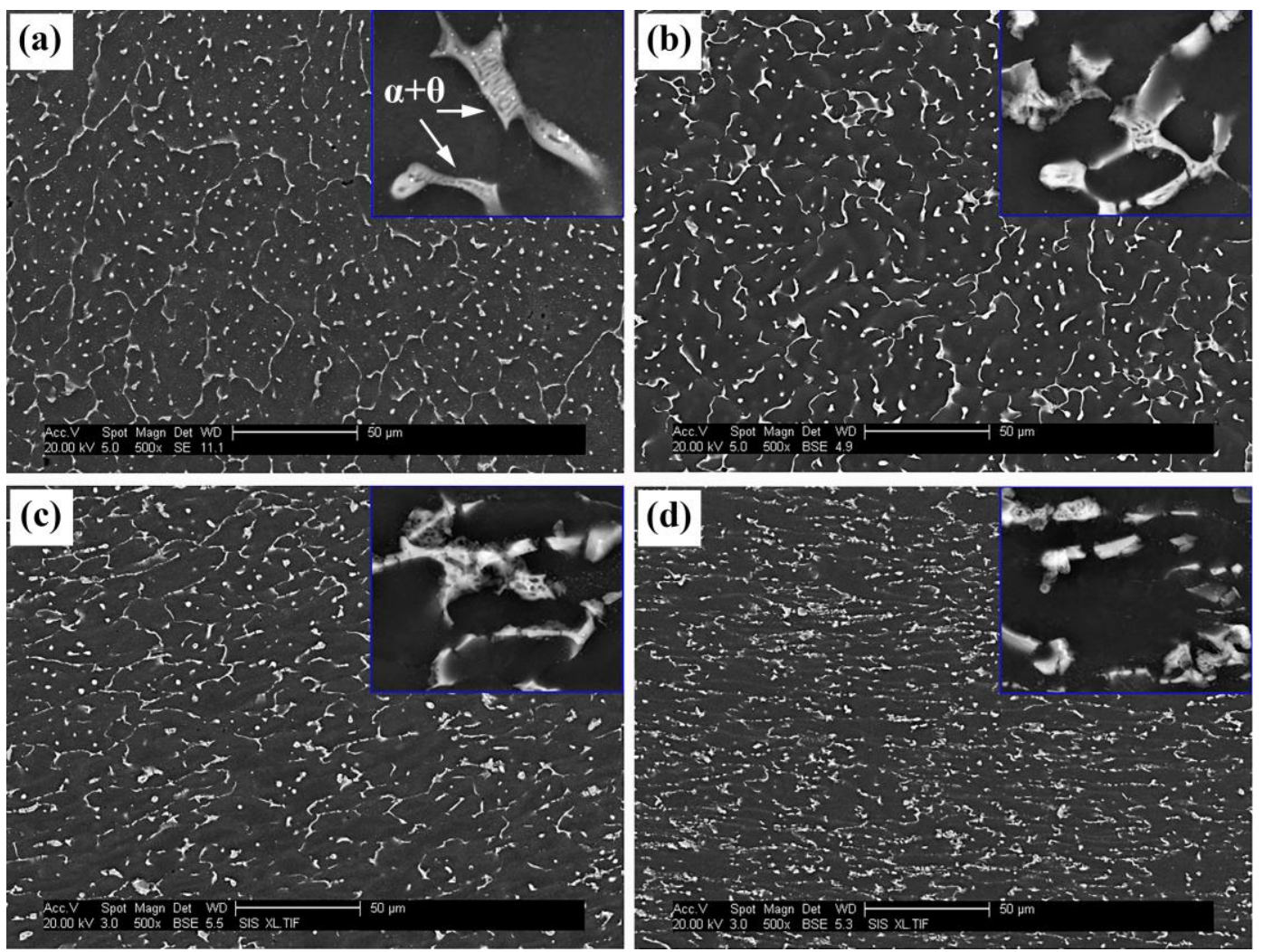

Fig. 8. Scanning electron micrographs for the WAAM 2219 alloys (a) as-deposited; (b-d) 15 kN, 30 
$\mathrm{kN}$ and $45 \mathrm{kN}$ inter-layer rolled.
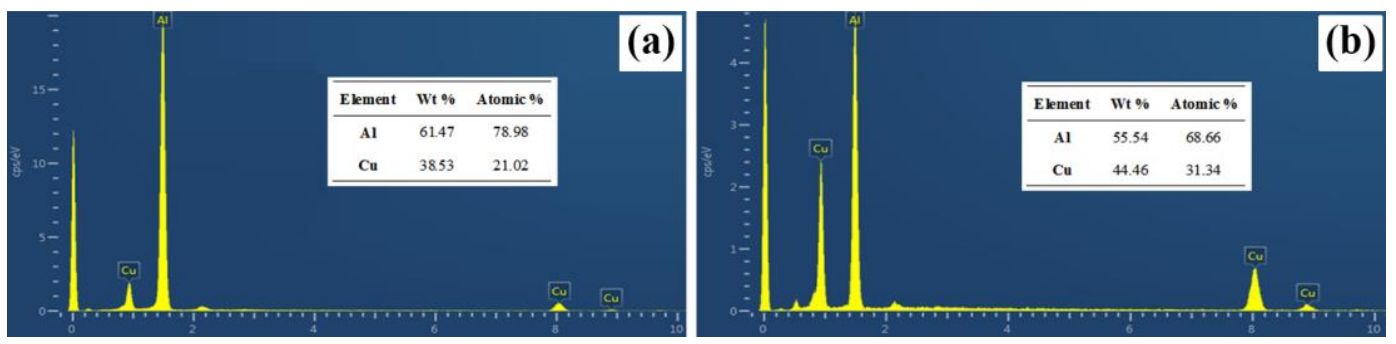

Fig. 9. Energy dispersive spectrometry analysis for the second phase in the WAAM 2219 alloys (a)

as-deposited; (b) T6 heat-treated.

Fig. 10 shows the OM images of the T6 treated alloys with or without rolling. Compared with the microstructure of the as-deposited alloy (as shown in Fig. 7(a)), the microstructure of this alloy became more homogeneous after the solution treatment and the artificial aging treatment. The dendrites that were contained within the grains of the as-deposited alloy were reduced in numbers. However, the post-deposition heat treatment led to a slight growth of the grain size. Comparatively, the $45 \mathrm{kN}$ inter-layer rolled $+\mathrm{T} 6$ heat treated alloy is characterized by the recrystallized microstructure, containing fine equiaxed grains. As shown in Fig. 10(b), significant grain size reduction can be observed for this alloy. This is the reason for the higher elongation of the rolled + heat-treated alloy than the heat-treated one without rolling.
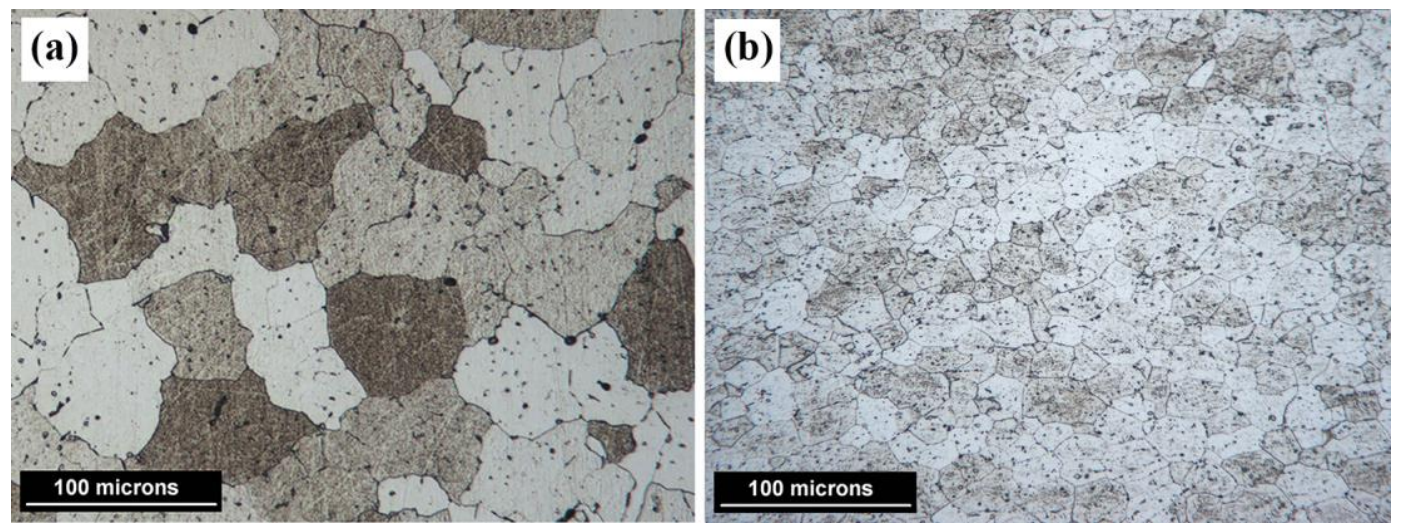

Fig. 10. Optical micrographs for the WAAM 2219 alloys (a) after-deposition T6 treated and (b)

$45 \mathrm{kN}$ rolled $+\mathrm{T} 6$ treated.

The SEM images of the second phase particles after heat treatment are shown in Fig. 11. White 
particles distributed uniformly in the matrix of the heat-treated specimens both with and without inter-layer rolling. The EDS analysis shown in Fig. 9(b) reveals that the white particles are $\theta$ phase. The sizes of these second phase particles were reduced compared with those in the as-deposited metal. This is because most of the eutectics dissolve when the temperature is close to the eutectic temperature, which is $543{ }^{\circ} \mathrm{C}$ for the 2219 alloy based on the Al-Cu phase diagram [24]. The particle size of the white phases for the $45 \mathrm{kN}$ rolled + T6 treated 2219 alloy were smaller than that of the non-rolled T6 treated alloy. This is because the eutectics in the rolled metal have been fractured into smaller pieces before the heat treatment. The higher solubility of $\mathrm{Cu}$ element under the solution treatment temperature results in a supersaturated solid solution by water quenching. This is the basis of precipitation strengthening.
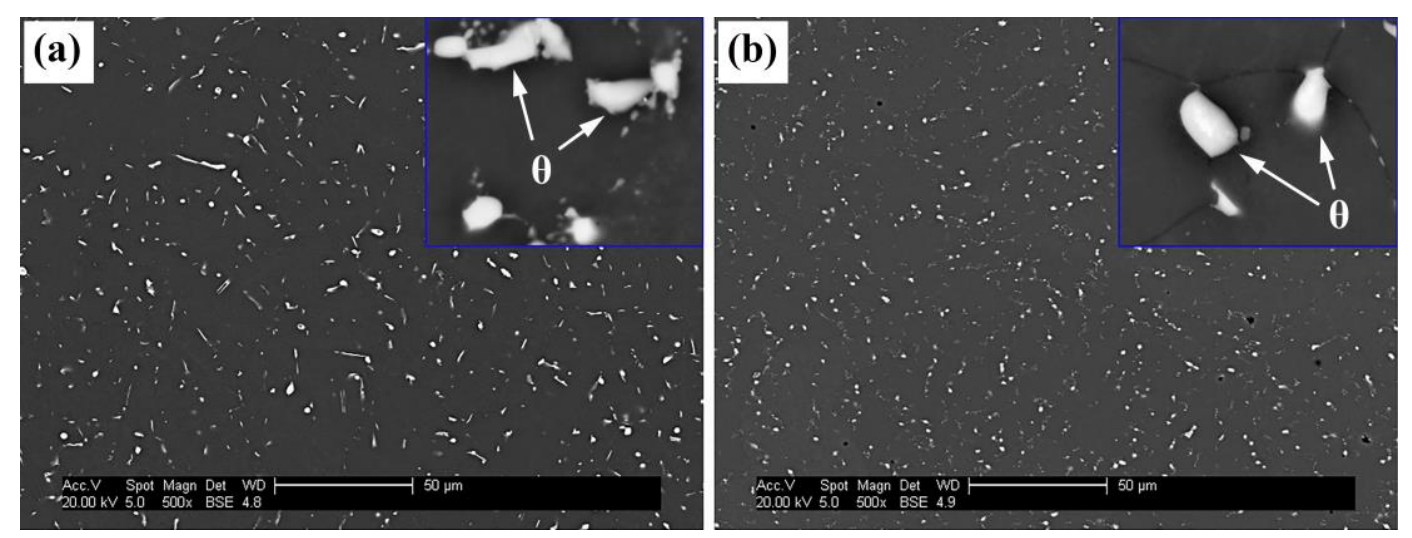

Fig. 11. Scanning electron micrographs for the WAAM 2219 alloys (a) after-deposition T6 treated and (b) $45 \mathrm{kN}$ rolled $+\mathrm{T} 6$ treated.

\subsection{Strengthening mechanism of heat treatment and cold working}

Fig. 12 shows the TEM bright field images of the WAAM 2219 alloys with various conditions. Different sized incoherent stable $\theta$ phase particles that formed in the as-deposited metal are shown in Fig. 12(a) (taken from the third layer beneath the top surface of the as-deposited wall). Differently to single pass welding, in the WAAM process material can be heated up several times during the multi-layer deposition. The heat from the subsequent deposited layers may induce a 
small amount of metastable $\mathrm{Al}_{2} \mathrm{Cu}$ precipitates forming in the previously deposited layers, as shown in Fig. 12(b) (taken from the middle part of the as-deposited wall). However this amount is not enough for a significant strengthening effect. These precipitates may grow upwards, losing the strengthening effect. Thus the absence of fine strengthening precipitates results in the low strength of the as-deposited WAAM 2219 alloy. Another reason is the solute segregation along grain and dendrite boundaries as shown in Fig. 8 (a) of the as-deposited alloy.
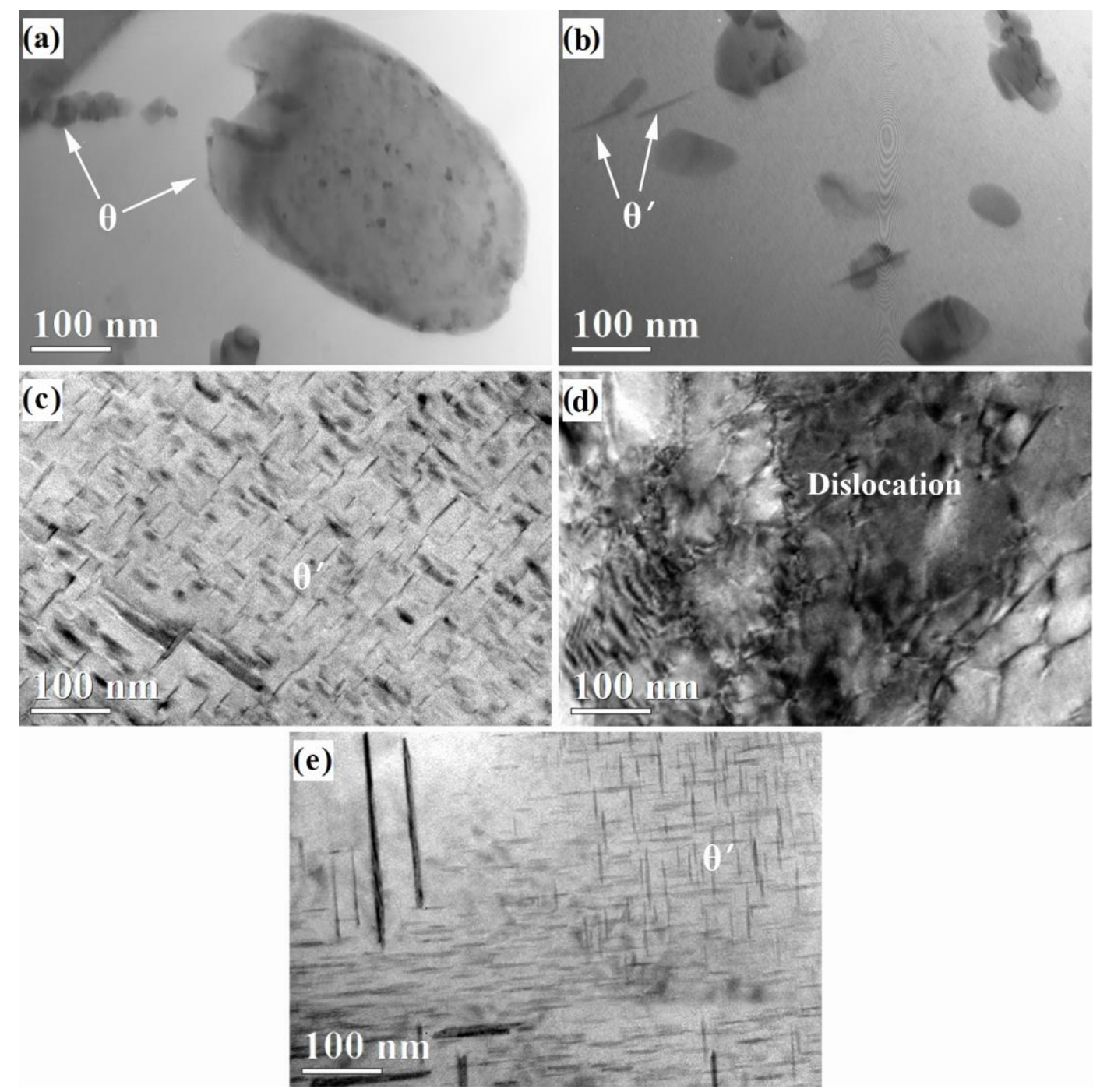

Fig. 12. Transmission electron microscopy images for the WAAM 2219 alloys (a) as-deposited (taken from the third layer beneath the top surface of the wall); (b) as-deposited (taken from the middle part of the wall); (c) after-deposition T6 treated; (d) $45 \mathrm{kN}$ rolled; (e) $45 \mathrm{kN}$ rolled + T6 treated. 

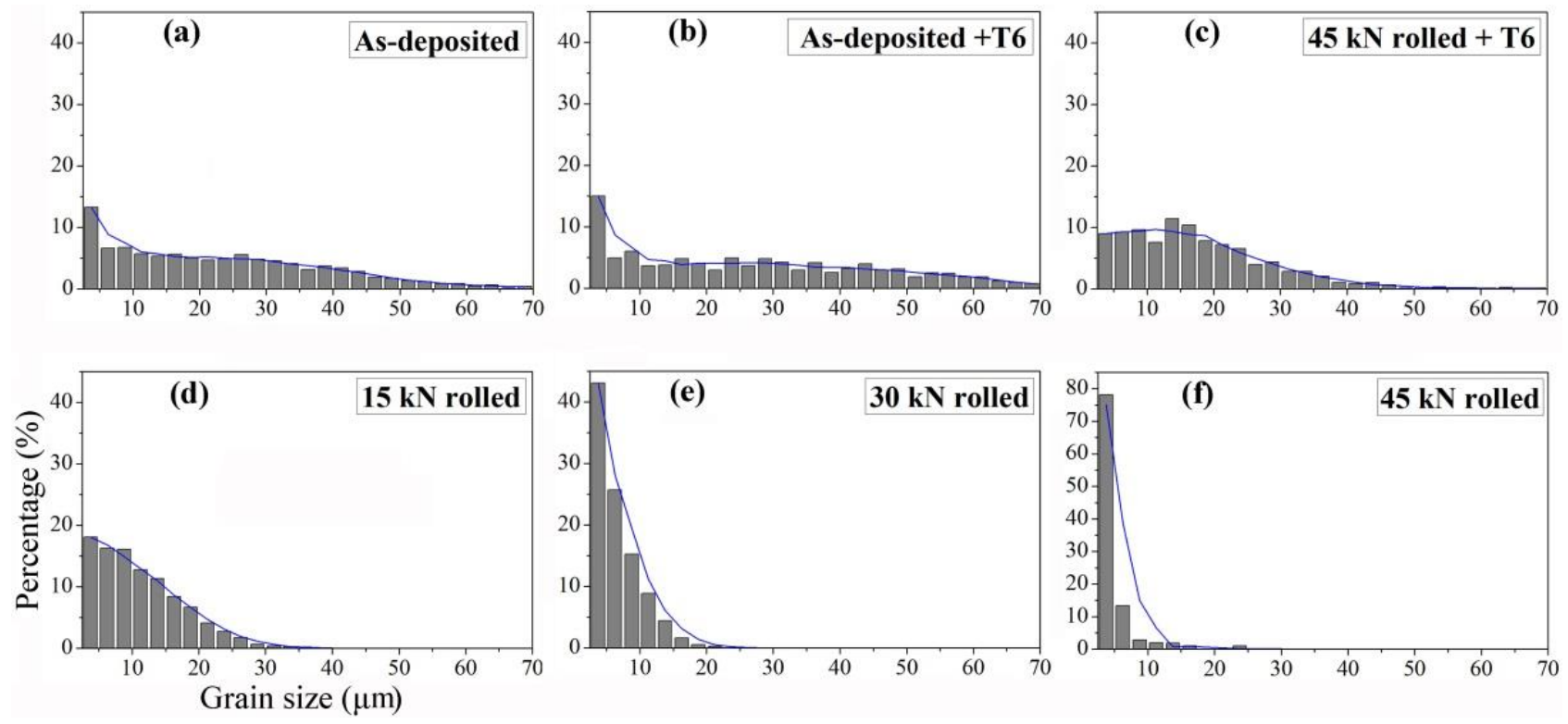

Fig. 13. Grain size distribution for the WAAM 2219 alloys (a) as-deposited; (b) after deposition T6 treated; (c) $45 \mathrm{kN}$ rolled + T6 treated; (d-f) $15 \mathrm{kN}, 30 \mathrm{kN}, 45 \mathrm{kN}$ inter-layer rolled.

The histograms of grain sizes for different WAAM specimens are shown in Fig. 13. Only grains larger than $3 \mu \mathrm{m}$ were counted due to the limitation of EBSD scanning resolution. Compared between Fig. 13 (a) and (b), the grains become more homogeneously distributed in size after heat treatment. Although the mean grain size was increased by $21 \%$ (from $26.7 \mu \mathrm{m}$ to $32.3 \mu \mathrm{m}$ ), significant improvements on both UTS and YS were observed for the deposited 2219 alloy after heat treatment. This can be attributed to the dissolution of most of the stable $\theta$ phases during solution treatment, as well as the formation of vast metastable precipitates during the subsequent aging process.

As Huang and Kou pointed out the size and distribution of $\mathrm{Al}_{2} \mathrm{Cu}$ play a major role in determining the mechanical properties for welded aluminum alloy 2219 [25]. Coarse second phase particles in as-deposited 2219 alloy have a weak impedance effect to dislocation movement. After T6 treatment fine needle-like precipitates were found densely and homogeneously distributed in the matrix as shown in Fig. 12(c). The length of these precipitated particles ranges from 50nm to 200 $\mathrm{nm}$. They are metastable $\theta^{\prime}$ phases as reported previously [26]. The strengthening mechanism for the 
T6 treated alloy is due to the obstacle effect of these fine precipitates, which hinders the motion of dislocation within the alloy. If the soaking duration time $(3 \mathrm{~h})$ in this study was prolonged, these precipitates may be coarsened, thereby reducing the strengthening effect.

Applying inter-layer rolling also improved the strength and hardness of the WAAM 2219 alloy. The main reason for the mechanical properties improvement is due to the distinct microstructures after rolling, which are characterized by dislocations with high-density (Fig. 12(d)) and fine sub-grains with relatively low misorientations. Fig. 13(d-f) show that the grain size becomes gradually smaller with increased rolling loads. The average grain size was reduced from $26.7 \mu \mathrm{m}$ to $12.8 \mu \mathrm{m}$ by applying $15 \mathrm{kN}$ rolling load, and this was further recued to $8.7 \mu \mathrm{m}$ and $7.7 \mu \mathrm{m}$ by applying $30 \mathrm{kN}$ and $45 \mathrm{kN}$ rolling load respectively. When a load of $45 \mathrm{kN}$ was applied, about $90 \%$ of the grains were compressed to around $5 \mu \mathrm{m}$ in size as shown in Fig. 13(f). This is because a great amount of finer sub-grains are formed after rolling by splitting the grains of the deposited alloy. Low misorientation is an indication of a sub-grain boundary. The grain boundary misorientation distributions for the investigated 2219 alloys - measured with EBSD - are shown in Fig. 14. Grain boundaries with misorientations larger than $15^{\circ}$ were defined as large angle ones and those with misorientations between $3-15^{\circ}$ were considered as small angle ones. Misorientations of less than $3^{\circ}$ were ignored because of the scanning resolution. Large angle grain boundaries account for nearly $95 \%$ of all the boundaries for the as-deposited alloy as well as for the after-deposition T6 treated alloy, indicating that they were in a nearly fully crystallized state. When the deposited metal was cold rolled with increasing loads, the fraction of small angle grain boundaries gradually increased. This indicates that, along with the increased deformation strain, a large amount of sub-grains were formed. With a $45 \mathrm{kN}$ rolling load, small angle boundaries account for over $76 \%$ of the total, demonstrating severe grain splitting. As shown in Fig. 15(a), substructure with low misorientation 
started to form due to the cell walls generated by dislocation climbing, sliding and tangling. The sub-boundaries are the accumulation of dislocations, exerting significant obstacle effect on dislocation movements and prompting resistance to deformations. In summary, the accumulated strains generated by plastic deformation result in dislocations piled up with a high density, thus improving the mechanical properties of the inter-layer rolled WAAM alloy.

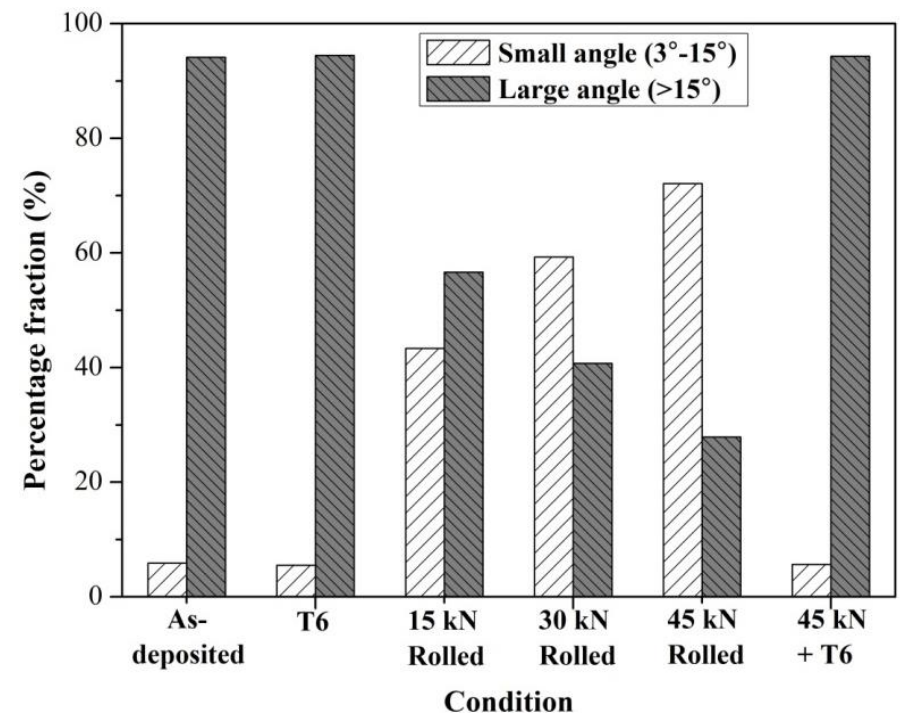

Fig. 14. Misorientations distribution for the as-deposited, inter-layer rolled and heat treated WAAM 2219 alloys.
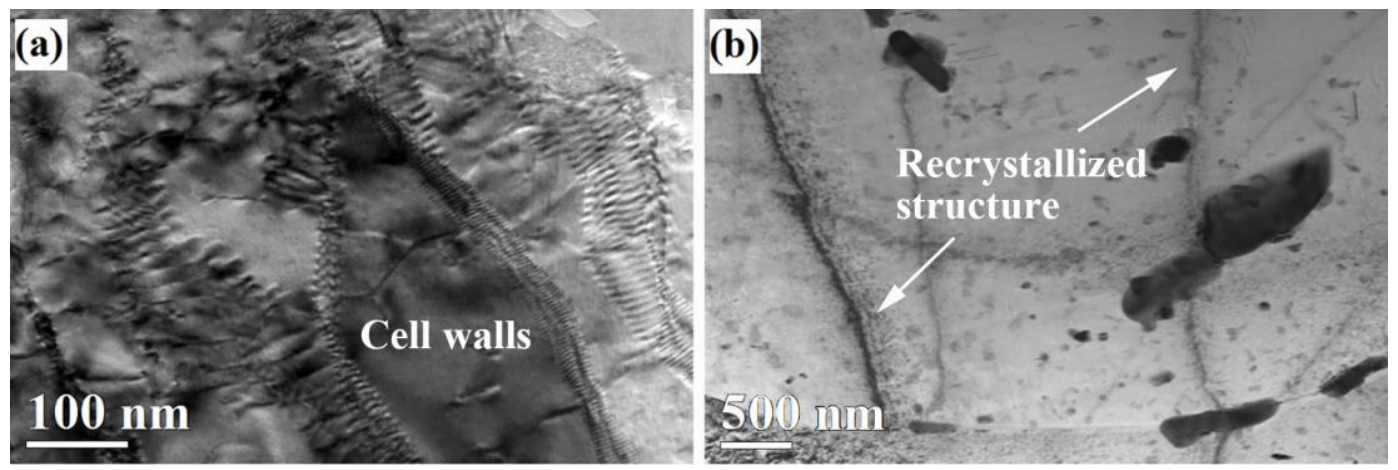

Fig. 15. TEM images for the $45 \mathrm{kN}$ rolled WAAM 2219 alloys (a) without T6 treated and (b) with T6 treated.

When the $45 \mathrm{kN}$ rolled specimen was heat treated, the grain sizes became more homogeneous, as shown in the analysis results of Fig. 13(c). The static recrystallization of the highly deformed 2219 alloy produces a mean grain size of $19.1 \mu \mathrm{m}$. The grain growth after heat treatment for the rolled 
metal is due to the imbalance between thermodynamic driving forces of the grains and the pinning forces impeding grain boundary migration [27]. The dispersed second phases normally provide grain boundaries pinning forces in stabilizing the grain structures. However along with the dissolution of the intermetallic phases under high temperature, the pinning forces gradually decrease. The sufficiently high mobility of the atoms and the dislocations led to the merging or growth of some grains. The recrystallized grain boundaries are shown in Fig. 15(b). Small angle grain boundaries are transformed into large angle grain boundaries through the absorption of dislocations [28] resulting in grain coarsening. As shown in Fig. 14, after T6 heat treatment the fraction of large angle boundaries for the $45 \mathrm{kN}$ rolled material increased to the same level as the as-deposited alloy with/without heat treatment. This indicates that a nearly complete recrystallization occurred after heat treatment for the rolled metal, resulting in more fined equiaxed grain structure (Fig. 10(b)).

Although the mean grain size of the $45 \mathrm{kN}$ rolled+T6 treated specimen is nearly half as the $\mathrm{T} 6$ treated one without inter-layer rolling, these two alloys have similar mechanical properties of hardness, strength. As shown in Fig. 12(e), the dislocation loops and piles up all disappeared after T6 treatment for the $45 \mathrm{kN}$ rolled specimen. Dense $\theta^{\prime}$ phase particles were uniformly scattered, indicating that precipitation strengthening provide the major contribution to the strength improvement. The reduction of grain size is not the main mechanism of the strength improvement for the 2219 alloy. The Hall-Petch relationship cannot be used to estimate the strength of the T6 treated WAAM 2219 alloy.

\section{Conclusion}


In this study, the strengthening effects and mechanisms of inter-layer rolling and post-deposition T6 heat treatment on WAAM 2219 aluminum alloy were investigated. The following conclusions can be drawn:

(1) The micro hardness and strength properties were gradually enhanced with the increasing rolling loads of $15 \mathrm{kN}, 30 \mathrm{kN}$ and $45 \mathrm{kN}$. The high-density dislocations and fine sub-grains with relatively low misorientations in the rolled alloy are the main reasons for the improvement of the tensile properties.

(2) The major strengthening mechanism of this alloy is precipitation strengthening. After T6 heat treatment, both the as-deposited and inter-layer rolled alloys achieved the similar levels of UTS and YS, which were above $450 \mathrm{MPa}$ and $305 \mathrm{MPa}$ respectively. These are higher than that of the wrought 2219-T6 alloy. After T6 treatment, the elongation of the 45 $\mathrm{kN}$ rolled material is higher than the as-deposited one due to the smaller grain size achieved after rolling.

(3) The fracture mode of the as-deposited, rolled, heat-treated WAAM samples were all dominated by ductile fracture, characterized in various dimple sizes.

\section{Acknowledgments}

The authors would like to give their gratitude to all the technician members in Welding Engineering and Laser Processing Centre in Cranfield University. This work was supported by the WAAMMat programme industry partners and the China Scholarship Council (No. 201306080042).

\section{References}

[1] E.A. Starke Jr, J.T. Staley, Prog. Aerosp. Sci. 32 (1996) 131-172.

[2] F. Wang, S. Williams, P. Colegrove, A.A. Antonysamy, Metall. Mater. Trans. A 44 (2013) 968-977. 
[3] F. Martina, J. Mehnen, S.W. Williams, P. Colegrove, F. Wang, J. Mater. Process.Technol. 212 (2012) 1377-1386.

[4] S.W. Williams, F. Martina, A.C. Addison, J. Ding, G. Pardal, P. Colegrove, Mater. Sci. Technol. (2015) 1743284715Y-0000000073.

[5] P. Naga Raju, K. Srinivasa Rao, G.M. Reddy, M. Kamaraj, K. Prasad Rao, Mater. Sci. Eng. A 464 (2007) 192-201.

[6] J.R. Davis, J.R. Davis, Aluminum and Aluminum Alloys, ASM international, Ohio, 1993.

[7] J. Gu, B. Cong, J. Ding, S.W. Williams, Y. Zhai, in: Proceedings of 25th Annual International Solid Freeform Fabrication Symposium, Austin, Texas, USA, 2014, pp. 45-458.

[8] A. Russell, K.L. Lee, Structure-Property Relations in Nonferrous Metals, John Wiley \& Sons, New Jersey, 2005.

[9] H. Liu, Y. Chen, J. Feng, Mater. Sci. Technol. 22 (2006) 237-241.

[10] V. Balasubramanian, V. Ravisankar, G.M. Reddy, Mater. Sci. Eng. A 459 (2007) 19-34.

[11] J. Ding, D. Wang, W. Ying, D. Hui, Trans. Nonferrous Metals Soc. 24 (2014) 1307-1316.

[12] S. Malarvizhi, K. Raghukandan, N. Viswanathan, Int. J. Adv. Manuf. Technol. 37 (2008) 294-301.

[13] S.P. Ringer, B.C. Muddle, I.J. Polmear, Metall. Mater. Trans. A 26 (1995) 1659-1671.

[14] S.R.K. Rao, G.M. Reddy, K.P. Rao, J. Mater. Process. Technol. 202 (2008) 283-289.

[15] P.A. Colegrove, H.E. Coules, J. Fairman, F. Martina, T. Kashoob, H. Mamash, L.D. Cozzolino, J. Mater. Process. Technol. 213 (2013) 1782-1791.

[16] F. Martina, S.W. Williams, P. Colegrove, in: Proceedings of the 24th Annual International Solid Freeform Fabrication Symposium, Austin, Texas, USA, 2013, pp. 490-496.

[17] G. Dance, Weld. Met. Fabr. 24 (1994) 216-222.

[18] B. Cong, J. Ding, S. Williams, Int. J. Adv. Manuf. Technol. 76 (2015) 1593-1606.

[19] P.S. Almeida, S. Williams, in: Proceedings of the 21st Annual International Solid Freeform Fabrication Symposium, Austin, Texas, USA, 2010, pp. 25-36.

[20] V. Sharma, K.S. Kumar, B.N. Rao, S. Pathak, Mater. Sci. Eng. A 502 (2009) 45-53.

[21] C. Huang, S. Kou, Weld. J. 80 (2001) 9-17.

[22] S. Malarvizhi, V. Balasubramanian, Weld. World 56 (2012) 105-119.

[23] G. Cao, S. Kou, Weld. J. (2005) 1-8. 
[24] V. Horn, K. Robertson, ed. Aluminum: Properties, Physical Metallurgy and Phase Diagrams, Vol. 1. American Society for Metals, Ohio, 1967.

[25] C. Huang, S. Kou, Weld. J., 80 (2001) 46-53.

[26] Z. Cvijović, G. Radenković, V. Maksimović, B. Dimčić, Mater. Sci. Eng. A 397 (2005) 195-203.

[27] I. Charit, R.S. Mishra, M.W. Mahoney, Scr. Mater. 47 (2002) 631-636.

[28] H. Li, Z. Li, M. Song, X. Liang, F. Guo, Mater. Des. 31 (2010) 2171-2176. 
2015-10-26

The strengthening effect of inter-layer cold working and post-deposition heat treatment on the additively manufactured Al-6.3Cu alloy

Gu, Jianglong

Elsevier

Gu J, Ding J, Williams S, et al., (2016) The strengthening effect of inter-layer cold working and post-deposition heat treatment on the additively manufactured Al-6.3Cu alloy. Materials Science and Engineering A: Structural Materials: Properties, Microstructures and Processing, Volume 651, January 2016, pp. 18-26

https://doi.org/10.1016/j.msea.2015.10.101

Downloaded from Cranfield Library Services E-Repository 